$$
\text { CONF- } 960850-6 \quad \text { AUL/ET/CP - } 89144
$$

\title{
PROCESSING AND CHARACTERIZATION OF Ag-CLAD Bi-2223 SUPERCONDUCTORS*
}

U. Balachandran, A.N. Iyer, R. Jammy, and M. Chudzik

Energy Technology Division

Argonne National Laboratory

Argonne, IL 60439
RECEIVED

SFP 191996

OSTI

M. Lelovic, P. Krishnaraj, and N.G. Eror

Materials Science and Engineering

University of Pittsburgh

Pittsburgh, PA 15261

P. Haldar

Intermagnetics General Corporation

Latham, NY 12110

\section{August 1996}

\begin{abstract}
The submitted manuscript has been created by the University of Chicago as Operator of Argonne National Laboratory ("Argonne") under Contract No. W-31-109-ENG-38 with the U.S. Department of Energy. The U.S Government retains for itself, and others acting on its behalf, a paid-up, nonexclusive, irrevocable worldwide license in said article to reproduce, prepare derivative works, distribute copies to the public, and perform publicly and display publicly, by or on behalf of the Government.
\end{abstract}

Submitted for publication in proceedings of Applied Superconductivity Conference, August 25-30, 1996, Pittsburgh PA.

*Work at ANL and part of the work at IGC is supported by the U.S. Department of Energy (DOE), Energy Efficiency and Renewable Energy, as part of a DOE program to develop electric power technalogy, under Contract W-31-109-Eng-38. 


\section{DISCLAIMER}

Portions of this document may be illegible in electronic image products. Images are produced from the best available original document. 


\section{DISCLAIMER}

This report was prepared as an account of work sponsored by an agency of the United States Government. Neither the United States Government nor any agency thereof, nor any of their employees, makes any warranty, express or implied, or assumes any legal liability or responsibility for the accuracy, completeness, or usefulness of any information, apparatus, product, or process disclosed, or represents that its use would not infringe privately owned rights. Reference herein to any specific commercial product, process, or service by trade name, trademark, manufacturer, or otherwise does not necessarily constitute or imply its endorsement, recommendation, or favoring by the United States Government or any agency thereof. The views and opinions of authors expressed herein do not necessarily state or reflect those of the United States Government or any agency thereof. 


\title{
Processing and Characterization of Ag-Clad Bi-2223 Superconductors
}

\author{
U. Balachandran, A.N. Iyer, R. Jammy, and M. Chudzik \\ Energy Technology Division, Argonne National Laboratory, Argonne, IL 60439 \\ M. Lelovic, P. Krishnaraj, and N.G. Eror \\ Materials Science and Engineering, University of Pittsburgh, Pittsburgh, PA 15261 \\ P. Haldar \\ Intermagnetics General Corporation, Latham, NY 12110
}

\begin{abstract}
Practical applications of high-temperature superconductors will be governed by their current transport and mechanical characteristics. With careful control of the processing parameters high-quality long-length mono- and multifilament $\mathrm{Bi}-2223$ conductors have been fabricated by the powder-in-tube technique. A critical current density $\left(\mathrm{J}_{\mathrm{C}}\right)$ of up to $1.2 \times 10^{4} \mathrm{~A} \mathrm{~cm}^{-2}$ has been observed at $77 \mathrm{~K}$ in a 1260 -m-long multifilament conductor containing 37 monocore filaments. A high-temperature superconducting magnet and a prototype transformer were fabricated and characterized from such long-length conductors. Efforts to further improve the current characteristics of the $\mathrm{Bi}-2223$ tapes resulted in the development of the wire-in-tube technique. $\mathrm{A} \mathrm{J}_{\mathrm{c}}$ value $>10^{5} \mathrm{~A} \mathrm{~cm}^{-2}$ at $77 \mathrm{~K}$ and in self field have been obtained in a Bi-2223 tape fabricated by the wirein-tube method. Extensive studies on the in-situ strain characteristics of the mono- and multifilament conductors have been conducted. Multilayer silver/superconductor composite tapes, fabricated by a novel chemical etching technique, were also observed to exhibit improved strain tolerance characteristics.
\end{abstract}

\section{INTRODUCTION}

Significant progerss has been made over the past few years in the development of high-temperature superconductors (HTS) for possible electric power and high-field magnet applications. However, for successful applications, it is critical that the HTS, which are brittle oxide ceramics, be fabricated into long-length conductors with high current transport properties and mechanical reliability. Because conventional techniques cannot be employed for fabricating commercially viable HTS, the powder-in-tube (PIT) technique was developed. The main advantage of the PIT process is that its metallurgical processes are all well established and can therefore be readily scaled up for mass production of long-length conductors. Several research groups have demonstrated high critical current density $\left(\mathrm{J}_{\mathrm{c}}\right)$ in short-length silver (Ag)-clad $\mathrm{Bi}-2223$ tapes fabricated by the PIT technique [1-3]. Intermagnetic General Corporation of Latham, NY, in collaboration with Argonne National Laboratory, has successfully fabricated mono- and multifilament Bi-2223 conductors in lengths of up to several hundred meters. These conductors have been cowound into prototype pancake-coils and racetrack-shaped solenoids. HTS magnets and a transformer fabricated with these coils were characterized at various temperatures and applied fields [3].

Recently, several research groups reported that most of the current in the Bi-2223 tape flows exclusively in a thin layer of highly aligned grains near the $\mathrm{Ag}$ sheath [4-6]. Existence of such a layer has been confirmed by microslice experiments [4], high-resolution transmission electron microscopy [5], and magneto-optical imaging [6]. Based on these results and the ever increasing demand for conductors with high current transport properties, effort was made to develop superconducting tapes by the Ag wire-in-tube (WIT) method. Development of the WIT technique was a joint effort between the University of Pittsburgh and Argonne National Laboratory. The WIT samples consist of an Ag layer that extends along the entire length of the tape, thereby reducing the difference between the nominal cross section of the superconductor and its actual current-carrying cross section.

Commercial HTS applications have been seriously hampered by their poor mechanical properties. During fabrication and service, the tapes are subjected to tensile, bending, and magnetic hoop stresses generated due to Lorentz force. These stresses can induce cracks in the material, thereby degrading the current transport properties of the tapes. Much effort is being expended to improve the strain tolerances of the tapes, by addition of $\mathrm{Ag}$ to the superconductor core or by use of alloy sheath material, or by developing composite tapes [7-9]. For these reasons, a good understanding of the electrical properties of these tapes under strain is an important engineering issue.

\section{EXPERIMENTAL PROCEDURE}

Partially reacted precursor powder, of composition $\mathrm{Bi}_{1.8} \mathrm{~Pb}_{0.4} \mathrm{Sr}_{2.0} \mathrm{Ca}_{2.2} \mathrm{Cu}_{3.0} \mathrm{O}_{\mathrm{x}}$, for the PIT process was prepared by a solid-state reaction of high-purity oxides and carbonates of $\mathrm{Bi}, \mathrm{Pb}, \mathrm{Sr}, \mathrm{Ca}$, and $\mathrm{Cu}$. The powder was then packed into Ag tubes, swaged, drawn through a series of dies, and then rolled to a thickness of $\approx 0.1 \mathrm{~mm}$. The tapes were subjected to a series of deformation process and heat treatment at $\approx 850^{\circ} \mathrm{C}$ in air. Multifilament conductors containing 37 and 61 filaments were fabricated by stacking monocore wires in a larger Ag tube and then drawing and rolling them to final size. Long lengths of mono- and multifilament conductors were fabricated by implementing a carefully designed two-step rolling and heat-treatment schedule. The long-length monofilament conductors were 
cowound in parallel to form pancake coils and racetrackshaped solenoids. HTS magnets were fabricated by stacking together and connecting in series a set of pancake coils. An HTS transformer with an iron core and capable of operating at $77 \mathrm{~K}$ was developed with the racetrack-shaped solenoid. A multilayer $\mathrm{Ag} /$ superconductor composite was fabricated by employing a novel etching technique, details of which are provided in [10]. The $\mathrm{Ag}$ sheath from one side of a pair of the tapes was etched while the other side was kept intact. The exposed cores were then aligned and joined with a single layer of a $25-\mu \mathrm{m}$-thick $\mathrm{Ag}$ foil sandwiched between them. The joined tapes were pressed and subjected to a series of thermomechanical treatments. Axial strain tolerance of mono- and multifilament conductors (the latter containing 61 filaments) was evaluated by subjecting the tapes to an in-situ tensile test. Critical current $\left(I_{c}\right)$ retention as a function of applied strain was measured at $77 \mathrm{~K}$ and in applied fields of 0 and $0.5 \mathrm{~T}$. The irreversible strain limit $\left(\varepsilon_{\mathrm{irr}}\right)$ is defined as that strain beyond which decrease in $I_{c}$ is irreversible. In-situ bend characteristics of the conductors were determined at $77 \mathrm{~K}$ and zero applied field with a custom-designed test fixture. Details of the test procedure is given [11]. Bend strain $(\varepsilon)$ was determined from the relationship $\varepsilon=t / 2 R$, where $t$ is the total thickness of the tape and $R$ is the radius of curvature. A bending test was condúcted on monofilament conductors with various superconductor fill factors and on the multilayer Ag/superconductor composite tape.

Freeze-dried powder of similar composition and heat treated at $800^{\circ} \mathrm{C}$ for $2 \mathrm{~h}$ in a $7 \% \mathrm{O}_{2}$ atmosphere was used for the WIT sample. Except for the introduction of the Ag wire, all processing was the same as reported earlier. Fig. 1, an optical photomicrograph of the WIT wire, shows that the Ag wire was slightly eccentric. The wire was drawn and rolled to a tape that was $=200 \mu \mathrm{m}$ thick. Short samples were cut and thermomechanically processed at various temperatures between 790 and $810^{\circ} \mathrm{C}$ in a $7 \% \mathrm{O}_{2}$ atmosphere. Transport property measurements were made by the standard four-point probe technique. The cross-sectional area of the sample was observed by scanning electron microscopy (SEM), and compositional analysis was accomplished by energy dispersive spectroscopy (EDS).

\section{RESULTS AND DISCUSSION}

High $I_{c}$ values in short samples have been achieved by a combination of uniaxial pressing and heat treatments. $I_{c}$ values above $40 \mathrm{~A}$ were typically attained at $77 \mathrm{~K}$, with the highest being $51 \mathrm{~A}$ in short samples subjected to a series of thermomechanical treatments. For fabricating long conductors, however, a more practical approach such as rolling has been adopted. At $77 \mathrm{~K}$ and zero applied field, $\mathrm{J}_{\mathrm{c}}$ values of $1.8 \times 10^{4} \mathrm{~A} \mathrm{~cm}^{-2}$ have been achieved in a $125-\mathrm{m}-$ long monofilament conductor. Similarly, as shown in Fig. 2 , a consistent $\mathrm{J}_{\mathrm{c}}$ of $1.2 \times 10^{4} \mathrm{~A} \mathrm{~cm}^{-2}$ has also been achieved in a 1260-m-long multifilament conductor containing 37 filaments. These results indicate that considerable progress is being made toward development of practical HTS cables.

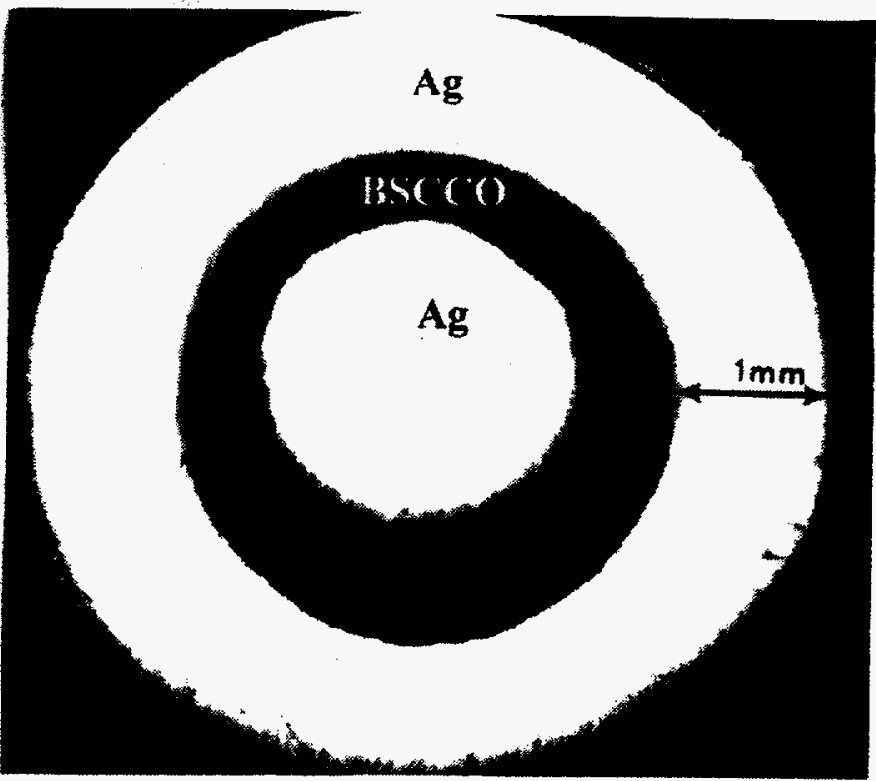

Fig. 1. Optical micrograph showing the cross section of the $\mathrm{Ag}$ wire-in-tube before rolling.

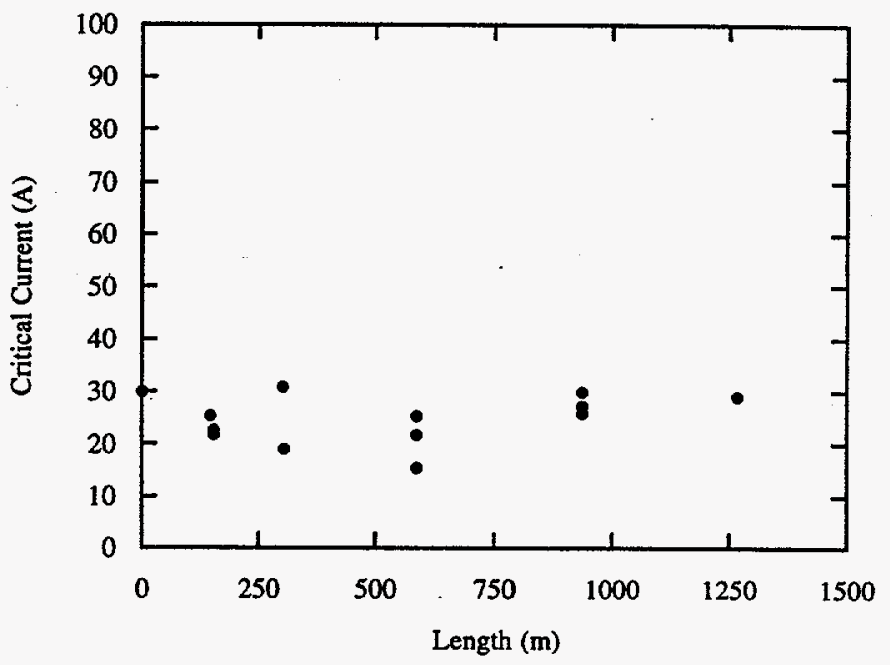

Fig. 2. Critical current vs. length of 1260 -m-long, 37-filament conductor at $77 \mathrm{~K}$.

An HTS magnet fabricated by stacking 20 pancake coils generated a field of $\approx 3.2 \mathrm{~T}$ at $4.2 \mathrm{~K}$ and zero applied field. Total conductor length was $2400 \mathrm{~m}$ and ampere turns at $4.2 \mathrm{~K}$ were $>250,000$. Another test magnet, fabricated with eight double-pancake coils and total conductor length of $770 \mathrm{~m}$ generated a field of $1 \mathrm{~T}$ at $4.2 \mathrm{~K}$ and $0.6 \mathrm{~T}$ at $27 \mathrm{~K}$, in a background field of $20 \mathrm{~T}$. Total length of the conductor in the magnet was $770 \mathrm{~m}$. Such HTS magnets can be used as 
inserts to form hybrid magnets with low-temperature superconducting coils, which are already in commercial use, to generate higher fields. A $0.25 \mathrm{KVA}$ HTS transformer was developed by IGC with the racetrack-wound solenoid and an iron core. The primary end of the transformer was made of $\approx 85 \mathrm{~m}$ of BSCCO tape, and the secondary end was $\approx 31 \mathrm{~m}$ long. Turns in the primary and secondary windings were 140 and 40 , respectively.

Microslice experiments conducted earlier along the rolling direction of the PIT tapes indicated that the $\mathrm{Bi}-2223$ grains adjacent to the $\mathrm{Ag}$ sheath are the high-J $\mathrm{J}_{\mathrm{c}}$ region. High resolution TEM revealed that these grains were $\mathrm{Bi}-2223$ with their (001) planes parallel to the Ag sheath. The interface between the $\mathrm{Ag}$ and the $\mathrm{Bi}-2223$ phase was well bonded and contained no transitional phases. Presence of such wellaligned $\mathrm{Bi}-2223$ grains has been further confirmed by magneto-optical imaging [6]. All these results imply that the central region of the superconductor core does not contribute much to the overall current-carrying capabilities of the PIT tapes. To improve the $J_{c}$ of the tapes, the center of the superconductor core was replaced with an $\mathrm{Ag}$ wire that, introduced along the length of the tape, provides a surface for the reaction-induced texturing that occurs during the thermomechanical treatment [12]. Furthermore, by replacing the central core with $\mathrm{Ag}$, the difference between the nominal cross-section area and the actual current-carrying crosssection was decreased. Fig. 3 shows the variation of $J_{c}$ as a function of heat treatment time at $800^{\circ} \mathrm{C}$ in a $7 \% \mathrm{O}_{2}$ atmosphere. The best result of $\mathrm{J}_{\mathrm{c}} \geq 2.0 \times 10^{5} \mathrm{~A} \mathrm{~cm}^{-2}$ ( $\mathrm{I}_{\mathrm{c}}$ was $22 \mathrm{~A})$ was obtained after $200 \mathrm{~h}$ and three intermediate uniaxial pressings. SEM revealed plate-like grains of Bi2223 phase with an average thickness $\approx 1 \mu \mathrm{m}$

To evaluate the strain tolerance characteristics of the Bi2223 tapes, in-situ axial and bending tests were conducted with custom-designed test fixtures. In-situ characterization circumvents the errors introduced by repeated handling and thermal cycling of the tapes during ex-situ tests. Axial tests at $77 \mathrm{~K}$ and $0.5 \mathrm{~T}$ applied field indicated that the multifilament conductor has better strain tolerance than the monofilament conductor, retaining more than $90 \%$ of their initial $I_{c}$ at $\geq 1 \%$ strain. While $\varepsilon_{\text {irr }}$ for the multifilament conductor was $\approx 1 \%$, that for the monofilament conductor was $\approx 0.2 \%$. Fig. 4 shows preliminary results on bending characteristics of monofilament conductors with various superconductor fill factors and on the multilayer composite tape. The plot shows that $\varepsilon_{\mathrm{in}}$ for the monofilament conductor increases with decrease in superconductor fill factor. Additionally, the multilayer tape (with a fill factor of $40 \%$ ) exhibited higher strain tolerance than the monofilament conductors, retaining $90 \%$ of its initial $\mathrm{I}_{c}$ at a bend strain of $1 \%$. Thus, the added Ag layer not only increases the strain tolerance of the tape, but by increasing the $\mathrm{Ag}$ /superconductor interfacial area should also increase the current transport properties of the tapes.

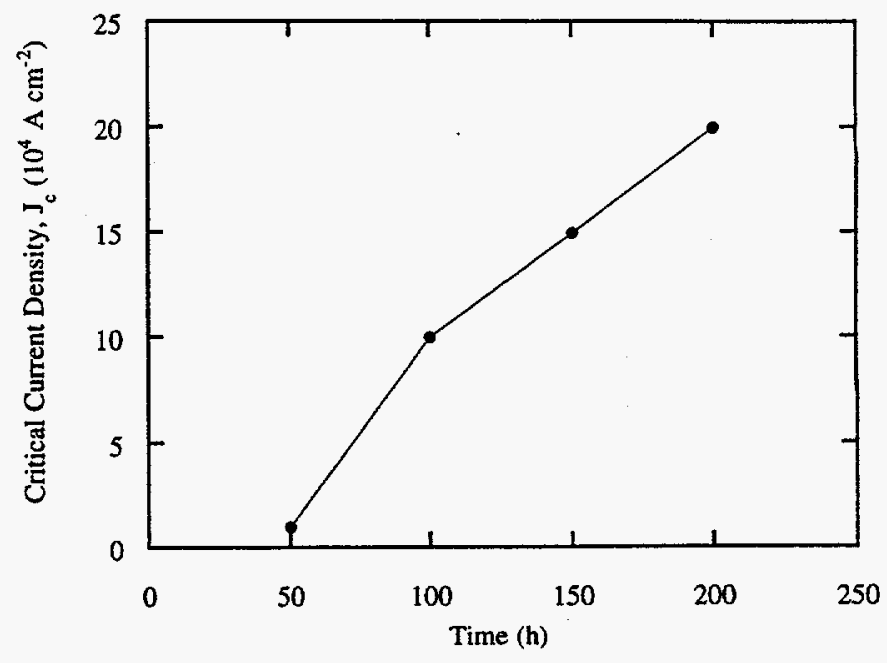

Fig. 3. Progression of $\mathrm{J}_{\mathrm{c}}$ with time at $800^{\circ} \mathrm{C}$ in a $7 \% \mathrm{O}_{2}$ atmosphere; each step is accompanied by uniaxial pressing.

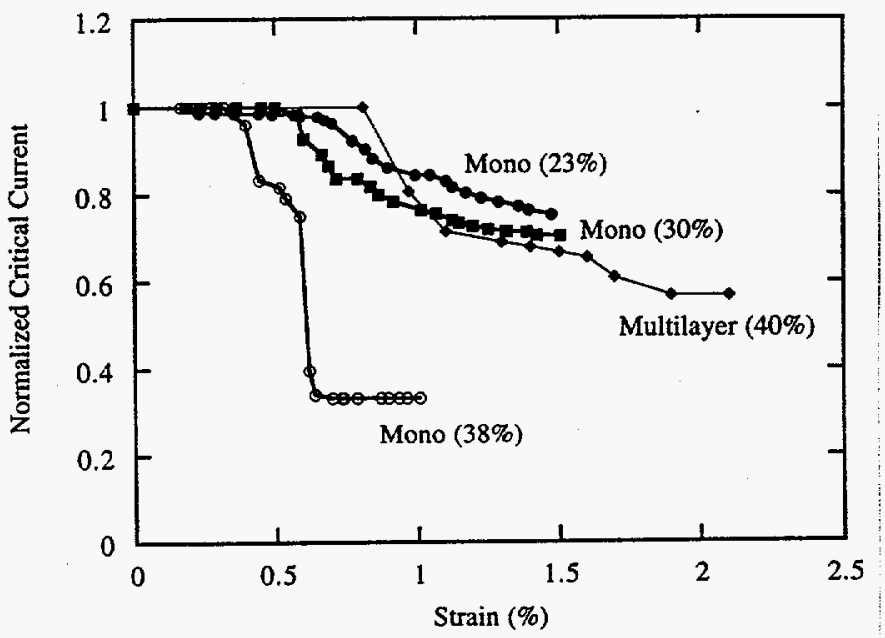

Fig. 4. Strain tolerance of Ag-clad BSCCO mono- and multilayer tape with various superconductor fill factors.

\section{CONCLUSIONS}

Long-length mono- and multifilament conductors with consistently high current transport properties have been fabricated by a carefully designed thermomechanical treatment process. HTS magnet and a prototype transformer have been fabricated from these long conductors. An HTS magnet containing $2400 \mathrm{~m}$ of tape generated a field of $3.2 \mathrm{~T}$ at $4.2 \mathrm{~K}$ and zero applied field. The magnet can be used, 
along with low-temperature superconductors, to form hybrid magnets for field-sensitive applications. By increasing the superconductor/Ag interface, we can improve not only the strain tolerance characteristics but also the current transport properties of the Bi-2223 tapes.

\section{ACKNOWLEDGMENT}

Work at ANL and part of the work at IGC is supported by the U.S. Department of Energy (DOE), Energy Efficiency and Renewable Energy, as part of a DOE program to develop electric power technology, under Contract W-31-109-Eng-38.

\section{REFERENCES}

[1] K. Sato ef al., "High-J Silver-Sheathed Bi-Based Superconducting Wires," IEEE. Trans. Mag., vol. 27, no. 2, pp. 1231-1238, 1991.

[2] Q. Li, K. Brodersen, H. A. Hjuler, and T. Freltoft, "Critical Current Density Enhancement in Ag-Sheathed Bi-2223 Superconducting Tapes," Physica C, vol. 217, no. 3-4, pp. 360-366, 1993.

[3] U. Balachandran, R. Jammy, M. Chudzik, A. N. Iyer, and P. Haldar, "Bi-Based Superconductors: Advances in Processing and Characterization," JOM, in press.

[4] M. Lelovic, P. Krishnaraj, N.G. Eror, A. N. Iyer, and U. Balachandran, "Transport Critical Current Density above $10^{5} \mathrm{~A}$ $\mathrm{cm}^{-2}$ at $77 \mathrm{~K} \mathrm{Bi}_{1.8} \mathrm{~Pb}_{0.4} \mathrm{Sr}_{2.0} \mathrm{Cr}_{2.2} \mathrm{Cu}_{3.0} \mathrm{O}_{\mathrm{y}}$ Superconducting Tapes Made by the Ag Wire-in-tube Method," Physica C, vol. 242, pp. 246-250, 1995.
[5] Y. Feng and D. C. Larblestier, "Texture Relationship and Interface Structure in $\mathrm{Ag}$-Sheathed $\mathrm{Bi}(\mathrm{Pb})-\mathrm{Sr}-\mathrm{Ca}-\mathrm{Cu}-\mathrm{O}$ Superconductor Tapes," Interface Sci., vol. 1, pp. 401-410, 1994.

[6] D. Larbalestier et al., "Visualizing Current Flow in High-Tc Superconductors," JOM, vol. 46, no. 12, pp. 20-22, 1994.

[7] J. P. Singh, J. Jo, N. Vasanthamohan, and R. B. Poeppel, "Role of $\mathrm{Ag}$ Additions in the Microstructural Development, Strain Tolerance, and Critical Current Density of Ag-Sheathed BSCCO Superconducting Tapes," J. Mater. Res., vol. 8, no. 10, pp. 24582464, 1993.

[8] J. Scwartz et al., "High Temperamure Mechanical Properties and High-Strength Sheaths for Powder-In-Tube Tapes," Appl. Supercond., vol. 2, no. 3-4, pp. 271-280, 1994.

[9] S. X. Dou, Y. C. Guo, and H. K. Liu, "Effect of Interfacial Layers on the Mechanical Properties of Ag-Clad Bi-Based Superconducting Composite Tapes," Supercond. Sci. Technol., vol. 6, pp. 195-198, 1993.

[10] J. Y. Huang et al., "Fabricating Superconducting Joints Between AgClad BSCCO Conductors," Appl. Supercond., vol. 3, no. 4, pp. 207-214, 1995.

[11] U. Balachandran, A. N. Iyer, R. Jammy, P. Haldar, and M. Suenaga, "Advances in Fabrication of Mono- and Multifilament Ag-Clad BSCCO Superconductors," Adv. Cryogenic Engg., in press.

[12] N. Mercant, J. S. Luo, V. A. Varoni, G. N. Riley, and W. L. Carter, "Reaction Induced Texture of (Bi, $\mathrm{Pb}_{2} \mathrm{Sr}_{2} \mathrm{C}_{2} \mathrm{Cu}_{3} \mathrm{O}_{10} \&$ AgComposite Conductors," Appl. Phys. Lett., vol. 65, pp. 1039-1041, 1994. 